\title{
Effects of Concentrate Supplementation on the Organic Matter Intake, Rumen Fermentation and Bacterial Community of Grazing Simmental Heifers
}

Hao Chen ( $\square$ chenhao9781@126.com )

Inner Mongolia Agricultural University

Chunjie Wang

Inner Mongolia Agricultural University

Simujide Huasai

Inner Mongolia Agricultural University

Aorigele Chen

Inner Mongolia Agricultural University

\section{Research}

Keywords: heifer, rumen fermentation, intake, bacteria, herbage

Posted Date: April 6th, 2021

DOI: https://doi.org/10.21203/rs.3.rs-376695/v1

License: (c) (i) This work is licensed under a Creative Commons Attribution 4.0 International License.

Read Full License 


\section{Abstract}

Background: In grazing systems, supplementation is an effective way to improve ruminant performance. Little is known regarding how concentrate supplementation affects rumen fermentation and the bacterial community of grazing animals in the grasslands of northern China. Therefore, the objective of this study was to examine the effects of concentrate supplementation on the organic matter intake, rumen fermentation and bacterial community of grazing Simmental heifers. Twenty-four 7-month-old heifers were randomly divided into a supplement group and a control group ( $\mathrm{n}=12$ per group). The control group heifers were grazed on a Leymus chinensis-based pasture without any supplementation (CON), while those in the supplement group (SUP) were grazed on the same grassland but received a concentrate supplement.

Results: Compared with the CON heifers, those in the SUP group had a greater $(P<0.05)$ total organic matter (OM) intake and digestibility. However, heifers from the CON group had a higher $(\mathrm{P}<0.05)$ herbage OM intake than those from the SUP group. The total VFA and NH3-N concentrations were significantly higher in the SUP group than in the CON group; of these, propionate, butyrate, and isobutyrate were also significantly increased in the SUP group. Furthermore, the acetate/propionate ratio was significantly decreased in the SUP group. Compared with the CON heifers, those in the SUP group had a higher bacterial richness. Firmicutes and Bacteroidetes were the two predominant bacteria at the phylum level, representing $54.32 \%$ and $38.59 \%$ of all sequences, respectively. Compared with the CON animals, the SUP animals showed significant $(p<0.05)$ increases in the relative abundance of Bacteroidetes and Verrucomicrobia, but supplementation did not affect the relative abundance of other bacteria at the phylum level. At the genus level, different diet treatments had an important effect on the relative abundance of the major genera (Fig. $3 \mathrm{C}$ ). The relative abundance of the genus Butyrivibrio was greater $(p<0.05)$ in the SUP group than in the CON group. The relative abundances of the genera Rikenellaceae_RC9_gut_group, Ruminococcaceae_UCG-010 and Ruminococcaceae_UCG-011 were higher $(p<0.05)$ in the CON group than in the SUP group.

Conclusions: In conclusion, providing $1.28 \mathrm{~kg}$ of supplement (DM basis) is a nutritional management strategy that can be adopted to improve the rumen fermentation, organic matter intake and digestibility of grazing heifers. Furthermore, supplementation has significant effects on the microbial community in the rumen of heifers, which might contribute to the anatomic development of the rumen, and these findings will contribute to the direction of future research in grazing heifers.

\section{Background}

Grazing is an important method of grassland utilization and plays a vital role in compensatory growth in grasses. For pastoral systems, pasture is the most cost-effective nutrient source [1]. However, overgrazing may result in an obvious decrease in the regenerative ability of grasslands and lead to grassland degradation [2]. Grassland covers $3.55 \times 10^{8} \mathrm{hm} 2$ in China, and many of these areas are used for grazing and are largely degraded by overgrazing $[3,4]$. The reduced availability and quality of pasture limit forage 
intake and productive performance. Therefore, in grazing systems, supplementation is an effective way to improve ruminant performance [5]. Compared with pasture-only diets, a grazing diet with concentrate supplementation in the late generation has been found to increase the body condition score and calf birth weight and improve carcass characteristics in finishing steers [6,7]. The rumen is the site of microbial lipid metabolism [8]. Many researchers have found that increasing dietary concentrate levels improves ruminal fermentation and short-chain fatty acid (FA) production by stimulating ruminal bacterial growth $[9,10]$. Manipulation of the diet by increasing the proportion of concentrate could consequently provide more VFAs for the rumen microbial population in pasture-grazed animals [11]. Dairy cows offered pasture only had a lower total VFA concentration and a higher ratio of acetic acid to propionic acid than those offered pasture plus barley [12].

A vast ensemble of ruminal microbes provide important metabolic capabilities for digesting cellulose-rich feed stuffs to sustain body maintenance and performance [13]. It is well known that feeding a large amount of grains to ruminants promotes high growth performance, which commonly results in ruminal microbiota dysbiosis and poor ruminant health [14]. Microbial biodiversity levels normally decrease with increasing amounts of concentrate in the diet. However, increasing the concentrate level has been shown to increase the abundance of Bacteroidetes in steers fed a total mixed ration. Intensive research has been done to describe the relationship between the roughage to concentrate ratio and rumen microbiota $[15,16]$. However, much less research has been conducted to explore the impact of concentrate supplementation on the composition of the rumen bacterial community and its response to changing nutrients in grazing cattle. In this study, we used 16S rRNA gene sequencing to determine the effect of concentrate supplementation on the ruminal microbiota profiles of grazing heifers.

\section{Methods}

\section{Animals, diets and feeding regimes}

Twenty-four 7-month-old heifers $(211.65 \pm 4.25 \mathrm{~kg} \mathrm{LW})$ were randomly divided into a supplement group and a control group ( $n=12$ per group). The heifers in the control group were grazed on a Leymus chinensis-based pasture without any supplementation (CON), where those in the supplement group (SUP) were grazed on the same grassland but received a concentrate supplement. All the heifers were released to graze during the daytime for the 60-day trial; the heifers in the SUP group were housed and individually received supplementary concentrate at a rate of $1.28 \mathrm{~kg}$ of DM/heifer per day $(1.4 \mathrm{~kg}$ of fresh weight/heifer per day) when returned to the enclosure after grazing. We observed that the animals consumed all the concentrate offered; that is, no refusals were recorded. The ration compositions and nutrient levels of the concentrate are listed in Table 1. All the heifers were free to take water throughout the experiment. The duration of the experiment was 68 days, and the heifers were offered the experimental diets for an 8-d dietary acclimatization period. Following this, the animals remained on their treatments for an additional $60 \mathrm{~d}$. Before adaptation, the heifers grazed the same sward as a single group and without any supplementation. 
Pasture quality was determined using the quadrat and shear method as described by Barthram et al. [17]. The quadrat samples were taken pregrazing by taking 3 quadrat $(1 \times 1 \mathrm{~m}$ quadrat) cuts per allocation ( 3 morning and 3 evening) and harvesting to $5 \mathrm{~cm}$. These samples were then pooled to determine $\mathrm{DM}$. The pasture samples were pooled at the beginning and at the end of the experiment for proximate analysis (DM, gross energy, ether extract, and CP) and ADF and NDF analyses (Table 2). Concentrate samples were taken weekly and pooled for nutritional analysis.

\section{Herbage and supplement intake}

Daily concentrate intake was measured for each heifer by the difference between the amount of supplement offered and refused. The animals were observed to consume all the concentrate offered; that is, no refusals were recorded. Herbage $\mathrm{OM}$ intake was determined from diet digestibility estimates and fecal production [18]. All the heifers were dosed with chromic oxide (Cr203), $12 \mathrm{~g} /$ heifer/day for 10 days from day 41 to day 50 of the experiment. $\mathrm{Cr} 203$ was administered in pellets mixed with the supplement. Fecal samples were collected from the rectum at 1930 during the last 3 days of $\mathrm{Cr} 203$ administration, placed in a forced-air oven at $60^{\circ} \mathrm{C}$ for $72 \mathrm{~h}$, and ground to pass through a $1 \mathrm{~mm}$ screen for further $\mathrm{Cr}$ concentration determination by atomic absorption spectrophotometry. Fecal production was calculated by relating the $\mathrm{Cr}$ daily dose and $\mathrm{Cr}$ fecal concentration. A recovery of $95 \%$ of $\mathrm{Cr}$ was assumed. Diet and herbage digestibility was calculated according to [19].

\section{Rumen sample collection and measurements}

Rumen fluid samples were collected from each animal prior to grazing on day 60 with an esophageal tube equipped with a strainer and a syringe, as described by Tian et al. [20]. To avoid contamination by saliva, the initial $50 \mathrm{~mL}$ of rumen fluid collected was discarded. Next, approximately $100 \mathrm{~mL}$ of rumen fluid was collected and immediately measured with a mobile pH meter (Rex PHS-3E, Shanghai INESA Scientific Instrument Co., Ltd., Shanghai, China). The rumen fluid was squeezed through four layers of cheesecloth to obtain filtrate, immediately frozen with liquid nitrogen, and stored at $-80^{\circ} \mathrm{C}$ prior to processing. The rumen fluid samples were analyzed for SCFAs using a gas chromatograph (GC-2010, Shimadzu, Japan) with SH-RTX-WAX capillary columns (30 $\mathrm{m} \times 0.25 \mu \mathrm{m} \times 0.25 \mathrm{~mm}$, Shimadzu, Japan). The VFA concentration was determined according to the methodology described by Palmquist and Conrad [21]. Ruminal ammonia (NH3-N) was determined by using a spectrophotometer (U-2900, Hitachi, Tokyo, Japan) following the method of Broderick and Kang [22].

\section{DNA extraction, 16S rRNA gene amplification and sequencing}

Genomic DNA was extracted from the ruminal fluid samples using an E.Z.N.A.® soil DNA Kit (Omega BioTek, Norcross, GA, USA) following the manufacturer's protocols. The extracted DNA was evaluated using a NanoDrop ND-2000 UV-vis spectrophotometer (Thermo Scientific, Wilmington, NC, USA), followed by agarose gel electrophoresis (1\%, wt/vol). The V3-V4 regions of rumen fluid bacterial 16S rRNA genes were amplified by PCR using primers 338F (5'-ACTCCTACGGGAGGCAGCA-3') and 806R (5'GGACTACHVGGGTWTCTAAT-3') as previously described [20]. 
PCR was performed in triplicate in a total reaction volume of $20 \mu \mathrm{L}$ containing $4 \mu \mathrm{L}$ of $5 \times$ FastPfu Buffer, $2 \mu \mathrm{L}$ of $2.5 \mathrm{mM}$ dNTPs, $0.8 \mu \mathrm{L}$ of forward primer $(5 \mu \mathrm{M})$ and reverse primer $(5 \mu \mathrm{M}), 0.4 \mu \mathrm{L}$ of FastPfu Polymerase, $0.2 \mu \mathrm{L}$ of BSA and $10 \mathrm{ng}$ of template DNA. PCR amplification was performed as follows: initial denaturation at $95^{\circ} \mathrm{C}$ for $3 \mathrm{~min}$; followed by $25-30$ cycles of denaturation at $95^{\circ} \mathrm{C}$ for $30 \mathrm{~s}$, annealing at $55^{\circ} \mathrm{C}$ for $30 \mathrm{~s}$, and extension at $72^{\circ} \mathrm{C}$ for $45 \mathrm{~s}$; and a final extension of $5 \mathrm{~min}$ at $72^{\circ} \mathrm{C}$. PCR products were selected by $2 \%$ agarose gel electrophoresis, further purified using the AxyPrep DNA Gel Extraction Kit (Axygen Biosciences, Union City, CA, USA) and then quantified using QuantiFluor ${ }^{\text {TM }}$-ST (Promega, USA) according to the manufacturers' protocols. Following amplification, paired-end sequencing libraries were constructed by Majorbio Bio-Pharm Technology Co. Ltd. (Shanghai, China). Paired-end sequencing $(2 \times 300 \mathrm{bp})$ was performed to sequence all the libraries on an Illumina MiSeq PE300 platform (Illumina, San Diego, CA, USA) according to standard protocols. Raw FASTQ files were quality-filtered by Trimmomatic and merged by FLASH as previously described [23]. The obtained sequences were clustered and divided into operational taxonomic units (OTUs) on the basis of $97 \%$ similarity using UPARSE (version $7.1 \mathrm{http}: / /$ drive5.com/uparse/) [24]. The taxonomy of each 16S rRNA gene sequence was provisionally analyzed using the RDP Classifier algorithm (http://rdp.cme.msu.edu/) against the Silva (V132) 16S rRNA database with a confidence threshold of $70 \%$ [25].

\section{Sequence processing and analysis}

Analysis was performed using the free online platform Majorbio I-Sanger Cloud Platform (www.isanger.com). Community richness and diversity, such as Good's coverage, observed species, and Chao1, Shannon, and Simpson indices, which are used to illustrate significant differences among samples, were assessed with the program MOTHUR (v.1.30.2.). The Kruskal-Wallis $\mathrm{H}$ test was used to identify phyla and genera that showed significant differences in abundance between groups (confidence interval method) with the Stats package in R and the SciPy package in PYTHON [26].

\section{Results}

\section{Organic matter intake, diet digestibility and rumen fermentation parameters}

The effect of concentrate supplementation on ruminal fermentation is presented in Table 3. The $\mathrm{pH}$ showed no differences between the different feeding groups. The total VFA and NH3-N concentrations were significantly higher in the SUP group than in the CON group; of these, propionate, butyrate, and isobutyrate were also significantly increased in the SUP group. Furthermore, the acetate/propionate ratio was significantly decreased in the SUP group. The heifers that received the concentrate supplement had a greater $(P<0.05)$ total OM intake and digestibility than the grazing heifers. However, there was no difference $(P>0.05)$ between the treatments for herbage OM digestibility. Furthermore, the heifers from the CON group had a higher $(P<0.05)$ herbage OM intake than those from the SUP group (Fig. 1).

\section{Richness, diversity estimates, and rumen bacterial composition}


A total of 1,846,851 high-quality sequences were generated. Based on $97 \%$ sequence identity, 470,520 bacterial sequences were assigned to 3,024 OTUs (Fig. 2). The results presented in Table 4 demonstrate that the Good's coverage of the microbial species of the different treatments was in the range of $98.1 \%-98.2 \%$, which indicated the accuracy and reproducibility of the sequencing. According to the Chao1 value $(1676.1 \pm 155.09$ vs. $2133.9 \pm 173.18, \mathrm{P}<0.05)$, there were significant differences in microbiota richness between the two groups, indicating higher richness in the SUP group (Table. 4). Principal coordinate analysis showed clear separations of the rumen bacteriome at the genus level in the heifers fed different diets based on the Bray-Curtis dissimilarity matrices.

Firmicutes and Bacteroidetes were the two predominant bacteria at the phylum level, representing $54.32 \%$ and $38.59 \%$ of all the sequences, respectively (Fig. $3 \mathrm{~A}$ ). Compared with the grazing animals, the supplemented animals showed significant $(p<0.05)$ increases in the relative abundance of Bacteroidetes and Verrucomicrobia, but the relative abundances of other bacteria at the phylum level were not affected (Fig. 3B). At the genus level, the different diet treatments had an important effect on the relative abundance of the major genera (Fig. $3 \mathrm{C}$ ). The relative abundance of the genus Butyrivibrio was greater ( $p$ $<0.05)$ in the SUP group than in the CON group. The relative abundances of the genera Rikenellaceae_RC9_gut_group, Ruminococcaceae_UCG-010 and Ruminococcaceae_UCG-011 were higher $(p<0.05)$ in the CON group than in the SUP group (Fig. 3D).

\section{Discussion}

It is generally accepted that changing the level of concentrate in ruminant diets can significantly affect the DMI and nutrient digestibility [27]. In the present study, the total OM intake increased significantly with concentrate supplementation, while the herbage $\mathrm{OM}$ intake was significantly decreased in heifers of the SUP group. This can be explained by the substitution rate for the concentrate. Concentration can provide more nutrients for the growth of rumen microorganisms and promote rumen fermentation. Consistent with the results of [28], the digestibility of $\mathrm{OM}$ increased significantly with increasing concentrate levels. In recent years, similar results in buffalos have been reported [29]. The reason for the improved OM digestibility of heifers by concentrate supplementation may be that the concentrate contains a large amount of nonfibrous carbohydrates, which can be rapidly fermented by rumen microorganisms, thus improving nutrient digestibility.

Ruminal $\mathrm{pH}$ is regulated through behavioral and physiological mechanisms under different nutrient levels [30]. Mckay et al. [31] reported a reduction in ruminal pH concentrate supplementation. In the present study, we found no difference in ruminal $\mathrm{pH}$, and the value for the two treatments was considered optimal for the growth of cellulolytic bacteria in the rumen. This may have been due to the difference in nutritive value of the concentrate supplement in that study (barley) compared with that in the current study (maize and soybean meal); additionally, maize has a higher rumen bypass for starch than barley, which may alter rumen conditions and subsequent concentrations of VFA. Concentrate supplementation altered 
rumen fermentation, as evidenced by increased total VFA production in the SUP group compared with the CON group. In addition to the increased total VFA concentration in the SUP group compared with the CON group, the SUP animals had increased concentrations of propionic and butyric acids. Datmann et al. [32] indicated that the concentration of ruminal NH3-N showed exponential growth with the dietary $\mathrm{CP}$ content. However, in our study, despite the $16 \mathrm{~g} \mathrm{CP} / \mathrm{kg}$ DM difference, the concentration of ruminal NH3-N was not affected by concentrate supplementation. This may be due to the equilibrium between the release of NH3-N in the rumen by microorganism fermentation, absorption via the rumen epithelium, and the liquid passage rate[33].

The pattern of rumen VFA production depends on the diet composition[34]. Ruminants obtain nearly 70$80 \%$ of their energy supply from VFAs[35]. According to Vlaeminck et al., diets containing high concentrations of NFC result in high propionate production[36]. In our study, ruminal acetate concentrations ranged from 61.36 to $62.28 \mathrm{mmol} / \mathrm{L}$, with no differences between treatments. However, compared to the animals in the unsupplemented group, those that received concentrate supplementation exhibited increased proportions of propionate and a decreased acetate-to-propionic acid ratio. This finding agrees with those of McCollum, who found that supplementation with cottonseed meal decreased the acetate:propionate ratio when compared to that in nonsupplemented cattle[37]. Butyrate is an important stimulator of the development of the rumen in calves[38]. Overall, supplementation with concentrate improved rumen fermentation due to more efficient utilization of the nutrients supplied by the herbage.

Rumen bacteria play an important role in rumen productivity and health. There are many factors that could affect the rumen bacterial community, of which diet composition is the most important factor. This study characterized for the first time the rumen bacterial community composition in grazing cattle under supplementation in temperate rangelands of northern China. Concerning the ruminal samples from our heifers, Firmicutes was the most abundant phylum (52\% and $57 \%$ ), followed by Bacteroidetes ( $41 \%$ and $36 \%$ for the CON and SUP heifers, respectively). The composition of the rumen bacterial population in this study was similar to that of the known bacterial population of cattle, which is dominated mainly by Firmicutes and Bacteroidetes, regardless of breed and diet[39,40]. In crossbred heifers, MartinezFernandez[41] also detected a preeminence of Bacteroidetes and Firmicutes; however, in their study, the abundance of Bacteroidetes was greatest in ruminal environments. Such contrasts between our study and that of Martinez-Fernandez are likely due to the diet. While the heifers in the latter study were grazed on dry tropical rangelands, our heifers were grazed ad libitum on a Leymus chinensis-dominant pasture. Moreover, our observations involving cattle grazing on temperate pastures agrees with the high ratio reported by other studies using yaks and dairy cattle fed fresh forage[42,43]. Thus, a consistent observation is emerging that the bacterial microbiota of ruminants consuming a diet comprised of more readily fermentable carbohydrates is dominated by Firmicutes.

Bacteroidetes has been observed to increase in numbers in cattle when consuming a diet high in lignocellulose (tropical hay)[44]. Many researchers have demonstrated that large fluctuations in the Firmicutes/Bacteroidetes ratio have been associated with changes in the relative amounts of dietary 
forages in ruminants $[45,46,47]$. In the current study, we observed that Bacteroidetes was significantly more abundant and that there was a lower Firmicutes/Bacteroidetes ratio in grazing heifers than in grazing heifers with concentrate supplementation, as reported in yaks and cattle. This may be due to the reduction in pasture DMI in comparison to heifers offered pasture only, and the decreased number of Bacteroidetes in the CON group indicated a decreased demand for bacterial species capable of metabolizing lignocellulose. The relative abundance of the phylum Bacteroidetes was significantly higher in the CON group than in the SUP group, and the phylum Firmicutes was more abundant in the SUP group than in the CON group, inferring that the main microbial communities were similar under different diet management practices but that each microbial flora proportion was different in the rumen under different diet management practices and would have a different fermentability. The genus Butyrivibrio was found

to be involved in the biohydrogenation of unsaturated C18 fatty acids, fiber degradation, and volatile fatty acid metabolism[48,49]. In the current study, we found that the relative abundance of Butyrivibrio was significantly higher in the SUP group than in the CON group. This result was in line with the study of LIU et al., who reported that high energy and protein levels in the diet could promote the growth of cellulolytic bacteria[30]. It has also been observed that the abundance of the genus Butyrivibrio was positively correlated with rumen weight and rumen papilla length in goats[50]. This finding suggested that concentrate supplementation might be beneficial to the anatomic development of the rumen.

\section{Conclusions}

In conclusion, providing $1.28 \mathrm{~kg}$ of supplement (DM basis) is a nutritional management strategy that can be adopted to improve the rumen fermentation, organic matter intake and digestibility of grazing heifers. Furthermore, supplementation has significant effects on the microbial community in the rumen of heifers, which might contribute to the anatomic development of the rumen, and these findings will contribute to the direction of future research in grazing heifers.

\section{Declarations}

\section{Authors' Contributions}

Conceptualization: A.C. and H.C.; data curation: A.C.; formal analysis: Q.F.; funding acquisition: H.C.; methodology: H.C. and A.C.; Software: C.W.; supervision: H.S.; writing-Original draft: H.C. and H.S.; writing-Review and editing: H.C., A.C., H.S., and C.W. All authors have read and agreed to the published version of the manuscript.

\section{Consent for publication}

Not applicable.

\section{Availability of data and materials}


The data sets used and/or analyzed during the current study are available from the corresponding author on reasonable request.

\section{Funding}

This work was funded by the National Key R\&D Program of China (2018 YFD0501700) and National Nature Science Foundation of China (project no. 31660677).

\section{Conflicts of Interest}

We certify that there are no conflict of interest with any financial organization regarding the material discussed in the manuscript.

\section{Ethics approval and consent to participate}

All the animal procedures were carried out according to the protocols approved by the College of Animal Science, Inner Mongolia Agricultural University, China. All the experimental animals were approved by the Institutional Animal Care and Use Committee in the College of Animal Science, Inner Mongolia Agricultural University, China.

\section{References}

1. Finneran E. Crosson P. O'Kiely P. Shalloo L. Forristal D. Wallace M.."Simulation Modelling of the Cost of Producing and Utilising Feeds for Ruminants on Irish Farms." Journal of Farm Management 14.2(2010)

2. Dong, S K, et al."Soil-Quality Effects of Grassland Degradation and Restoration on the QinghaiTibetan Plateau." Soil Science Society of America Journal 76.6(2012).

3. Jian Ni."Carbon storage in grasslands of China." Journal of Arid Environments 50.2(2002)

4. Yan L, Zhou G, Zhang F. Effects of different grazing intensities on grassland production in China: a meta-analysis. PLoS ONE. 2013; 8(12):1466-1475.

5. Marcella T P R, Maciel Fernandes R, Custódio, Letícia, et al. Effect of supplementation level on performance of growing Nellore and its influence on pasture characteristics in different seasons[J]. Italian Journal of Animal Science, 2018:1-11.

6. Da Silva A G , Paulino, Mário Fonseca, Detmann E, et al. Energetic-protein supplementation in the last 60 days of gestation improves performance of beef cows grazing tropical pastures[J]. Journal of Animal ence \& Biotechnology, 2017, 8(1):78.

7. Della Rosa M M , Pouzo L B , Pavan E. Meat and fat quality traits of grazing steers supplemented with corn grain and increasing amounts of flaxseed[J]. Livestock ence, 2017, 208:51-54.

8. Sun $X Q$, Gibbs $S \mathrm{~J}$. Diurnal variation in fatty acid profiles in rumen digesta from dairy cows grazing high-quality pasture[J]. Animal Feed ence \& Technology, 2012, 177(3-4). 
9. Da Silva-Marques R P , Zervoudakis J T , Nakazato L , et al. Ruminal Microbial Populations and Fermentation Characteristics in Beef Cattle Grazing Tropical Forage in Dry Season and Supplemented with Different Protein Levels[J]. Current Microbiology, 2019.

10. Zhou K, Bao Y , Zhao G . Effects of dietary crude protein and tannic acid on rumen fermentation, rumen microbiota and nutrient digestion in beef cattle[J]. Archives of Animal Nutrition, 2018:1-14.

11. Doreau, M., Ferlay, A., 1995. Effect of dietary lipids on nitrogen metabolism in the rumen: a review. Livest. Prod. Sci. 43, 97-110.

12. Z, C, McKay, et al. The effect of concentrate supplementation type on milk production, dry matter intake, rumen fermentation, and nitrogen excretion in late-lactation spring-calving grazing dairy cows.[J]. Journal of dairy science, 2019.

13. Kim $Y H$, Nagata $R$, Ohkubo A, et al. Changes in ruminal and reticular $\mathrm{pH}$ and bacterial communities in Holstein cattle fed a high-grain diet[J]. BMC Veterinary Research, 2018, 14(1).

14. Sandra Costa-Roura,Joaquim Balcells,Gabriel de la Fuente,Jesús Mora-Gil,Núria Llanes,Daniel Villalba. Effects of protein restriction on performance, ruminal fermentation and microbial community in Holstein bulls fed high-concentrate diets[J]. Animal Feed Science and Technology,2020,264.

15. Henderson G , Cox F , Kittelmann S, et al. Effect of DNA Extraction Methods and Sampling Techniques on the Apparent Structure of Cow and Sheep Rumen Microbial Communities[J]. Plos One, 2013, 8.

16. Kim, Y.H., Nagata, R., Ohkubo, A., Ohtani, N., Kushibiki, S., Ichijo, T., Sato, S., 2018. Changes in ruminal and reticular $\mathrm{pH}$ and bacterial communities in Holstein cattle fed a high-grain diet. BMC Vet. Res. 14, 310

17. Barthram GT (1985) Experimental techniques: The HFRO sward stick. In: The hill farming research organization biennial report 1984/1985. Hill Farming Research Organization, Penicuik, pp 29-30

18. Coates, D., Penning, P., t Mannetje, L., Jones, R., 2000. Measuring animal performance. In: t'mannetje, L., Jones, R.M. (Eds.), Field and Laboratory Methods for Grassland and Animal Production Research, CAB International, Wallingford, pp. 353-402.

19. Effect of restricting time at pasture and concentrate supplementation on herbage intake, grazing behaviour and performance of lactating dairy cows

20. Tian K, Liu J, Sun Y, Wu Y, Chen J, Zhang R, Dong G. Effects of dietary supplementation of inulin on rumen fermentation and bacterial microbiota, inflammatory response and growth performance in finishing beef steers fed high or low-concentrate diet. Animal Feed Science and Technology,2019,258.

21. Palmquist DL, Conrad HR. 1971. Origin of plasma fatty acids in lactating cows fed high grain or high fat diets. J Dairy Sci. 54:1025-1033.

22. Broderick G A, Kang J H. 1980. Automated simultaneous determination of ammonia and total amino acids in ruminal fluid and in vitro media. Journal of Dairy Science, $63,64-75$ 
23. Liu, HJ; Xu, TW; Xu, SX; Ma, L; Han, XP; Wang, XG; Zhang, XL; Hu, LY; Zhao, N; Chen, YW; Pi, L; Zhao, $X Q$. Effect of dietary concentrate to forage ratio on growth performance, rumen fermentation and bacterial diversity of Tibetan sheep under barn feeding on the Qinghai-Tibetan plateau. PEERJ 2019;7: e7462.

24. Edgar, R.C. (2013). UPARSE: highly accurate OTU sequences from microbial amplicon reads. Nature Methods 10, 996.

25. Quast, C., Pruesse, E., Yilmaz, P ., Gerken, J., Schweer, T ., Yarza, P ., et al. (2013). The SILVA ribosomal RNA gene database project: improved data processing and web-based tools. Nucleic acids research 41(Database issue), D590-D596. doi: 10.1093 /nar/gks1219

26. Zhang Jun,Shi Haitao,Wang Yajing,Cao Zhijun,Yang Hongjian,Li Shengli. Effect of Limit-Fed Diets With Different Forage to Concentrate Ratios on Fecal Bacterial and Archaeal Community Composition in Holstein Heifers.[J]. Frontiers in microbiology,2018,9.

27. GIZACHEW A. Comparative feedlot performance of Washera and Horro sheep fed different roughage to concentrate ratio. Master Thesis. Haramaya: Haramaya University, 2012.

28. Ribeiro CS, Granja-Salcedo YT, Messana JD, Neto AJ, Canesin RC, Fiorentini G, Alarcon MF, Berchielli TT. 2015. Feeding increasing concentrate to Tifton 85 hay ratios modulated rumen fermentation and microbiota in Nellore feedlot steers. J Agric Sci. 153:1116-1127.

29. Nampoothiri, Vinu M.; Mohini, Madhu; Malla, Bilal A. Growth performance, and enteric and manure greenhouse gas emissions from Murrah calves fed diets with different forage to concentrate ratios Animal Nutrition 2018;4:215-21

30. National Academies of Sciences, E., and Medicine (2016). Nutrient Requirements of Beef Cattle: Eighth Revised Edition. Washington, DC: The National Academies Press.

31. Z, C, McKay, et al. The effect of concentrate supplementation type on milk production, dry matter intake, rumen fermentation, and nitrogen excretion in late-lactation spring-calving grazing dairy cows.[J]. Journal of dairy science, 2019.

32. Detmann, E., Valente, E.E.L., Batista, E.D., Huhtanen, P., 2014. An evaluation of the performance and effificiency of nitrogen utilization in cattle fed tropical grass pastures with supplementation. Livest. Sci. 162, 141-153.

33. Lifeng, Dong, Binchang, et al. Effects of Dietary Forage Proportion on Feed Intake, Growth Performance, Nutrient Digestibility, and Enteric Methane Emissions of Holstein Heifers at Various Growth Stages.[J]. Animals : an open access journal from MDPI, 2019, 9(10).

34. Fan Q , Wanapat M , Hou F . Chemical Composition of Milk and Rumen Microbiome Diversity of Yak, Impacting by Herbage Grown at Different Phenological Periods on the Qinghai-Tibet Plateau[J]. Animals, 2020, 10(6):1030.

35. Vlaeminck,B., Fievez, V., Cabrita, A.R.J., Fonseca, A.J.M., Dewhurst, R.J., 2006. Factors affecting oddand branched-chain fatty acids in milk: a review. Anim. Feed Sci. Technol. 131, 389-417 
36. Mccollum F T , Galyean M L , Krysl L J , et al. Cattle Grazing Blue Grama Rangeland Diets and Rumen Fermentation I. Seasonal[J]. Journal of Range Management, 1985, 38(6):539-543

37. L. D , da, Silva, et al. Effects of silage crop and dietary crude protein levels on digestibility, ruminal fermentation, nitrogen use efficiency, and performance of finishing beef cattle[J]. Animal Feed Science \& Technology, 2016.

38. Sandra Costa-Roura,Joaquim Balcells,Gabriel de la Fuente,Jesús Mora-Gil,Núria Llanes,Daniel Villalba. Effects of protein restriction on performance, ruminal fermentation and microbial community in Holstein bulls fed high-concentrate diets[J]. Animal Feed Science and Technology,2020,264.

39. Kong F , Gao Y , Tang M , et al. Effects of dietary rumen-protected Lys levels on rumen fermentation and bacterial community composition in Holstein heifers[J]. Applied Microbiology and Biotechnology, 2020(814).

40. W N M , Tacheba G, Makore J . Seasonal diet preference of cattle, sheep and goats grazing on the communal grazing rangeland in the Central District of Botswana[J]. African Journal of Agricultural Research, 2015, 10(29):2791-2803.

41. Changed Caecal Microbiota and Fermentation Contribute to the Benefificial Effffects of Early Weaning with Alfalfa Hay, Starter Feed, and Milk Replacer on the Growth and Organ Development of Yak Calves

42. Noel Samantha J,Attwood Graeme T,Rakonjac Jasna,Moon Christina D,Waghorn Garry C,Janssen Peter $\mathrm{H}$. Seasonal changes in the digesta-adherent rumen bacterial communities of dairy cattle grazing pasture.[J]. PloS one,2017,12(3).

43. Joshua C. McCann,Leanne M. Wiley,T. David Forbes,Francis M. Rouquette,Luis O. Tedeschi. Relationship between the Rumen Microbiome and Residual Feed Intake-Efficiency of Brahman Bulls Stocked on Bermudagrass Pastures[J]. PLOS ONE,2014,9(3).

44. Carvalho P H V , Pinto A C J , Millen D D , et al. Effect of cattle breed and basal diet on digestibility, rumen bacterial communities, and eating and rumination activity[J]. Journal of Animal ence(5):5.

45. Ke Tian,Junhui Liu,Yawang Sun,Yongjiang Wu,Juncai Chen,Ruiming Zhang,Tianle He,Guozhong Dong. Effects of dietary supplementation of inulin on rumen fermentation and bacterial microbiota, inflammatory response and growth performance in finishing beef steers fed high or low-concentrate $\operatorname{diet}[J]$. Animal Feed Science and Technology,2019,258.

46. Yo-Han Kim,Rie Nagata,Akira Ohkubo,Natsuki Ohtani,Shiro Kushibiki,Toshihiro Ichijo,Shigeru Sato. Changes in ruminal and reticular $\mathrm{pH}$ and bacterial communities in Holstein cattle fed a high-grain $\operatorname{diet[J].~Yo-Han~Kim;Rie~Nagata;Akira~Ohkubo;Natsuki~Ohtani;Shiro~Kushibiki;Toshihiro~Ichijo;Shigeru~}$ Sato,2018,14(1).

47. Zhu Z., S. Hang, S. Mao and W. Zhu. 2014. Diversity of Butyrivibrio group bacteria in the rumen of goats and its response to the supplementation of garlic oil. Asian-Australas J Anim Sci. 27: 515 179186. 
48. Boeckaert Charlotte,Vlaeminck Bruno,Fievez Veerle,Maignien Lois,Dijkstra Jan,Boon Nico. Accumulation of trans C18:1 fatty acids in the rumen after dietary algal supplementation is associated with changes in the Butyrivibrio community.[J]. Applied and environmental microbiology,2008,74(22).

49. Q. Liu,C. Wang,H.Q. Li,G. Guo,W.J. Huo,C.X. Pei,S.L. Zhang,H. Wang. Effects of dietary protein levels and rumen-protected pantothenate on ruminal fermentation, microbial enzyme activity and bacteria population in Blonde d'Aquitaine $\times$ Simmental beef steers[J]. Animal Feed Science and Technology,2017,232.

50. Jiao J , Huang J , Zhou C , et al. Taxonomic Identification of Ruminal Epithelial Bacterial Diversity during Rumen Development in Goats[J]. Applied and Environmental Microbiology, 2015, 81(10):35023509 .

\section{Tables}

Table 1 Composition of concentrate fed to Simmental heifers

\begin{tabular}{|ll|}
\hline Ingredient & Composition (\%) \\
\hline Maize & 47.75 \\
\hline Wheat bran & 25.25 \\
\hline Soybean meal & 21.00 \\
\hline Limestone & 2.0 \\
\hline CaHPO $_{4}$ & 1.0 \\
\hline NaCl $^{2.0}$ & 1.0 \\
\hline Premix & 2.0 \\
\hline Total \% $^{1}$ & 100 \\
\hline
\end{tabular}

${ }^{1}$ The premix provided the following nutrients per kilogram of the concentrate: VA 10000 IU, VD4000 IU, VE $30 \mathrm{IU}$, biotin $0.15 \mathrm{mg}$, folic acid $1.0 \mathrm{mg}$, nicotinic acid $10 \mathrm{mg}, \mathrm{Cu} 15 \mathrm{mg}, \mathrm{Fe} 75 \mathrm{mg}, \mathrm{Mn} 100 \mathrm{mg}, \mathrm{Zn} 60 \mathrm{mg}$, I $0.25 \mathrm{mg}$, Se $0.40 \mathrm{mg}$,Co $0.15 \mathrm{mg}$.

Table 2 Chemical composition of forage and concentrate fed to Simmental heifers 


\begin{tabular}{|lll|}
\hline Fraction (\% DM) & Forage & Concentrate \\
\hline Dry matter (\%) & 42.08 & 91.36 \\
\hline Crude protein & 10.67 & 18.22 \\
\hline Neutral detergent fibre (NDF) & 48.03 & 21.63 \\
\hline Acid detergent fibre (ADF) & 33.11 & 14.88 \\
\hline Ether extract (EE) & 3.05 & 3.19 \\
\hline ME (MJ/kg) & 8.59 & 13.15 \\
\hline
\end{tabular}

Table 3 Effects of concentrate supplementation on rumen fermentation of grazing heifers.

\begin{tabular}{|c|c|c|c|c|}
\hline \multirow[b]{2}{*}{ Items } & \multicolumn{2}{|c|}{ Treatments } & \multirow[t]{2}{*}{ SEM } & \multirow[t]{2}{*}{$P$-value } \\
\hline & $\mathrm{CON}$ & SUP & & \\
\hline $\mathrm{pH}$ & 7.13 & 6.95 & 0.096 & 0.213 \\
\hline Ammonia nitrogen, $\mathrm{NH}_{3}-\mathrm{N}(\mathrm{mg} / \mathrm{dL})$ & 9.63 & 11.58 & 0.184 & 0.046 \\
\hline Total VFA (mmol/L) & 86.72 & 96.48 & 2.965 & 0.007 \\
\hline Acetate $(\mathrm{mmol} / \mathrm{L})$ & 61.36 & 62.28 & 2.174 & 0.426 \\
\hline Propionate(mmol/L) & 16.15 & 19.96 & 0.613 & 0.013 \\
\hline Butyrate(mmol/L) & 5.76 & 10.34 & 0.914 & $<0.001$ \\
\hline Isobutyrate(mmol/L) & 0.57 & 1.01 & 0.102 & $<0.001$ \\
\hline Valerate(mmol/L) & 0.62 & 0.57 & 0.076 & 0.068 \\
\hline Isovalerate(mmol/L) & 2.26 & 2.32 & 0.082 & 0.297 \\
\hline Acetate/Propionate & 3.79 & 3.12 & 0.131 & 0.016 \\
\hline
\end{tabular}

Table 4 Alpha diversities of bacteria in the rumen fluid of the heifers among the two groups. 


\begin{tabular}{|llllll|}
\hline Estimators & CON-Mean & CON-Sd & SUP-Mean & SUP-Sd & $P$-value \\
\hline Shannon & 5.9793 & 0.18178 & 5.8987 & 0.23121 & 0.3974 \\
\hline Simpson & 0.0079495 & 0.0015943 & 0.011487 & 0.0015575 & 0.1647 \\
\hline Ace & 1947.2 & 143.32 & 1990.3 & 151.07 & 0.5217 \\
\hline Chao & 1676.1 & 155.09 & 2120.9 & 173.18 & 0.0373 \\
\hline Coverage & 0.98218 & 0.0011391 & 0.98141 & 0.0019094 & 0.2881 \\
\hline
\end{tabular}

Figures 

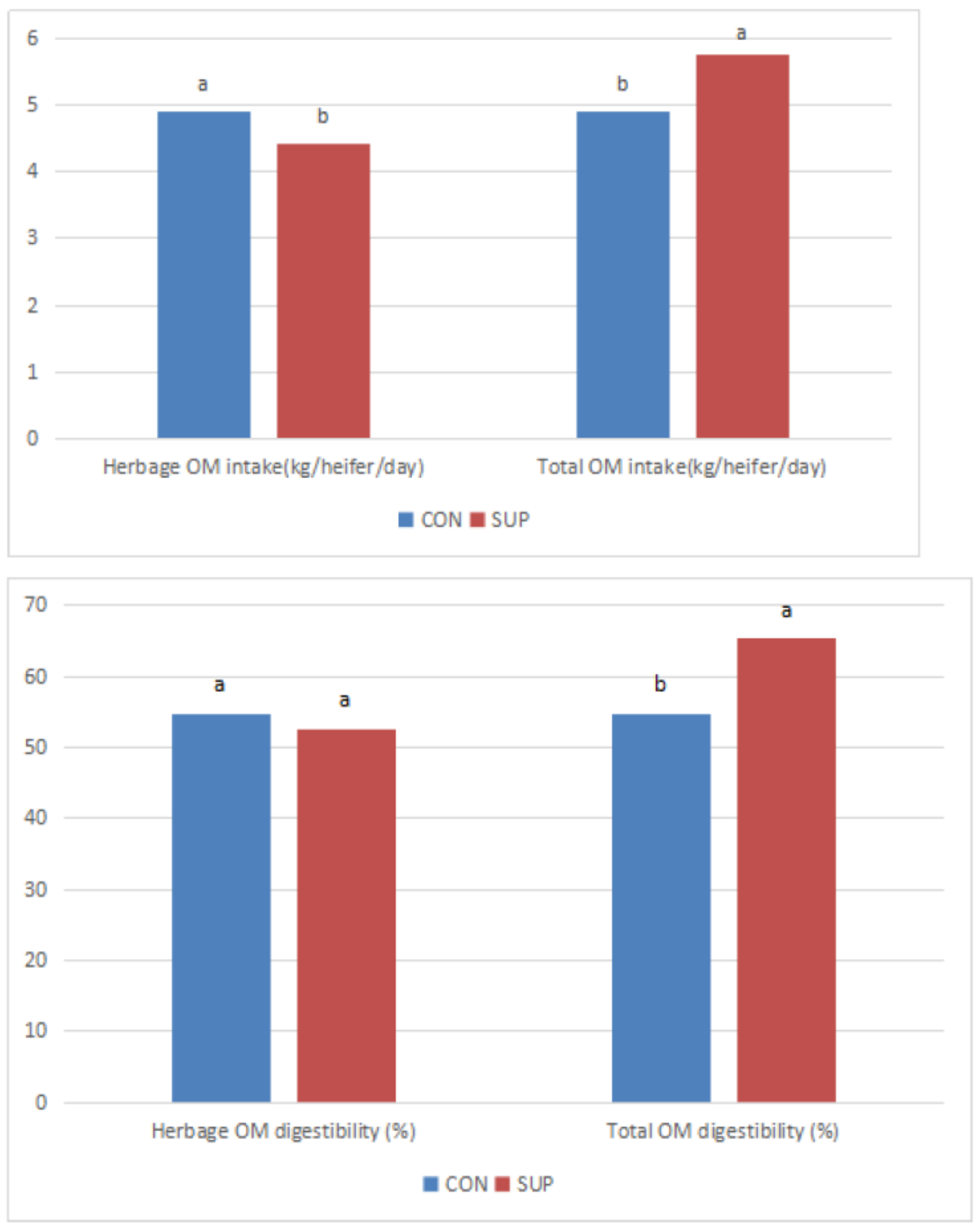

\section{Figure 1}

Effect of concentrate supplementation on herbage and total OM intake and digestibility of grazing heifers. a total OM intake in two groups of grazing heifers. $b$ total OM digestibility of grazing heifers. Boxes with a different letter are significantly different at $\mathrm{P}<0.05$ by $\mathrm{t}$-test analyses. CON, without supplementation; SUP, with supplementation; 


\section{Venn}

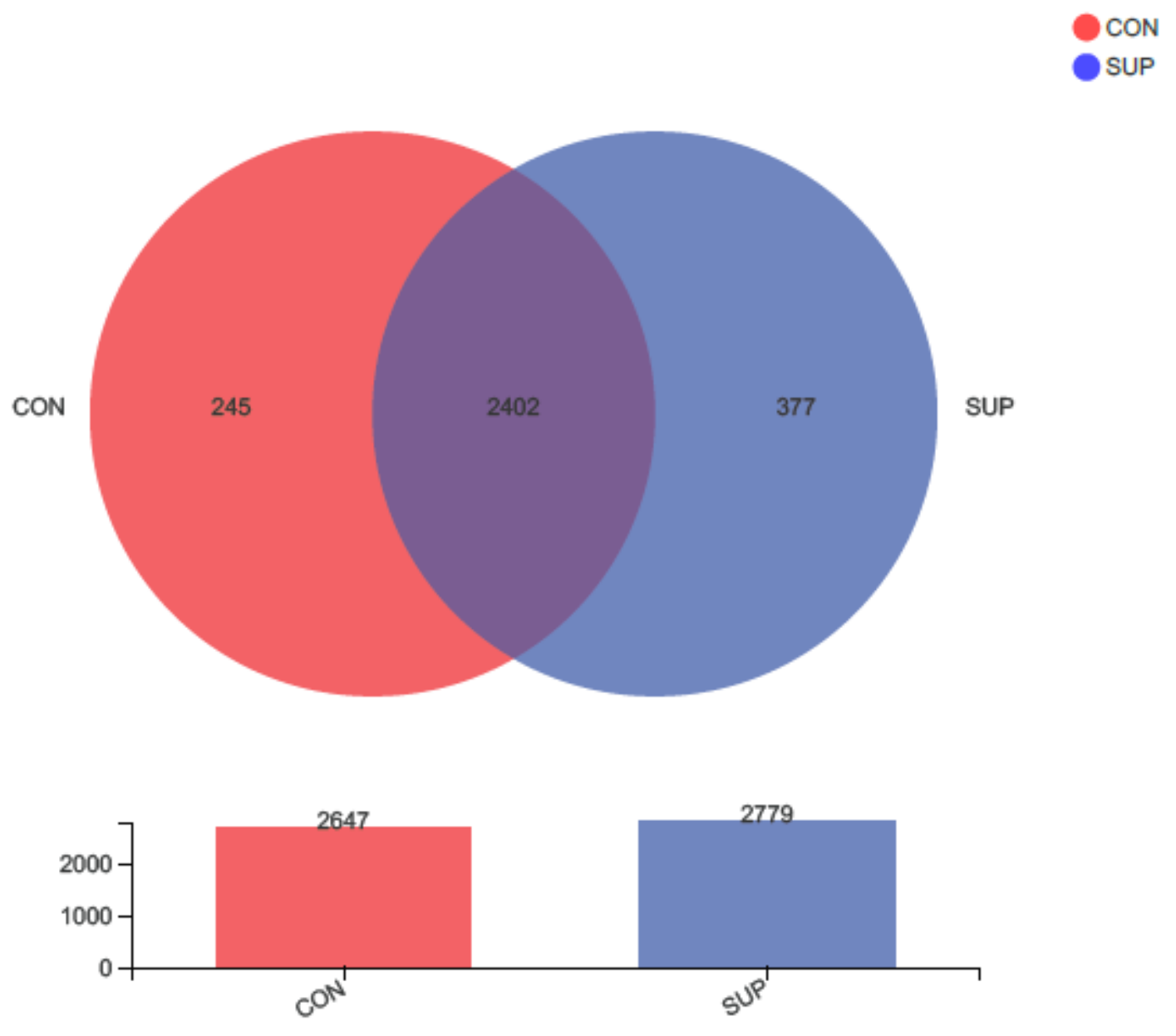

Figure 2

16S rRNA gene sequences in different dietary groups. A Venn diagram illustrating the overlap of bacterial OTUs at a $3 \%$ dissimilarity level for Groups CON and SUP. Ruminal microbial community difference between the different feeding paradigm groups $(n=12)$. 


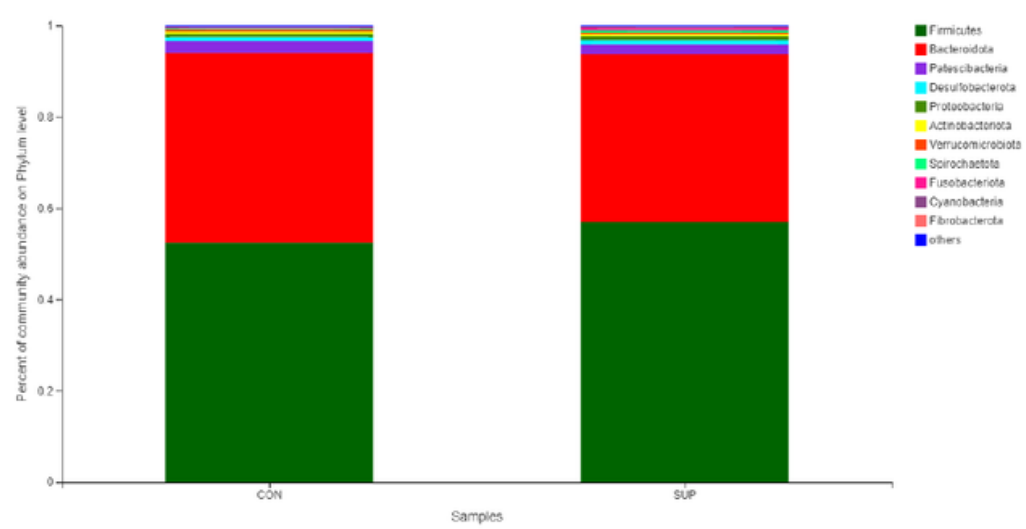

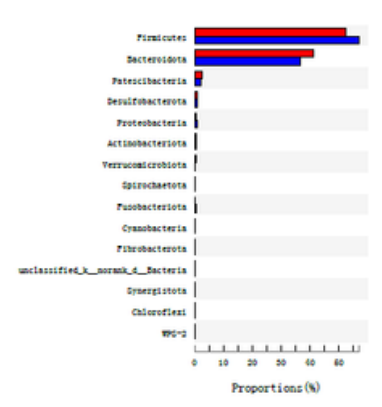

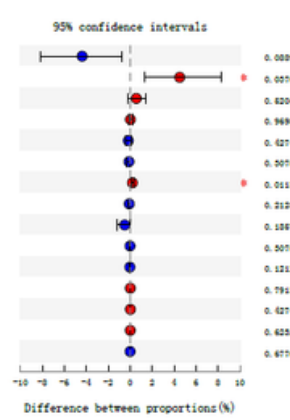

$\frac{2}{8}$
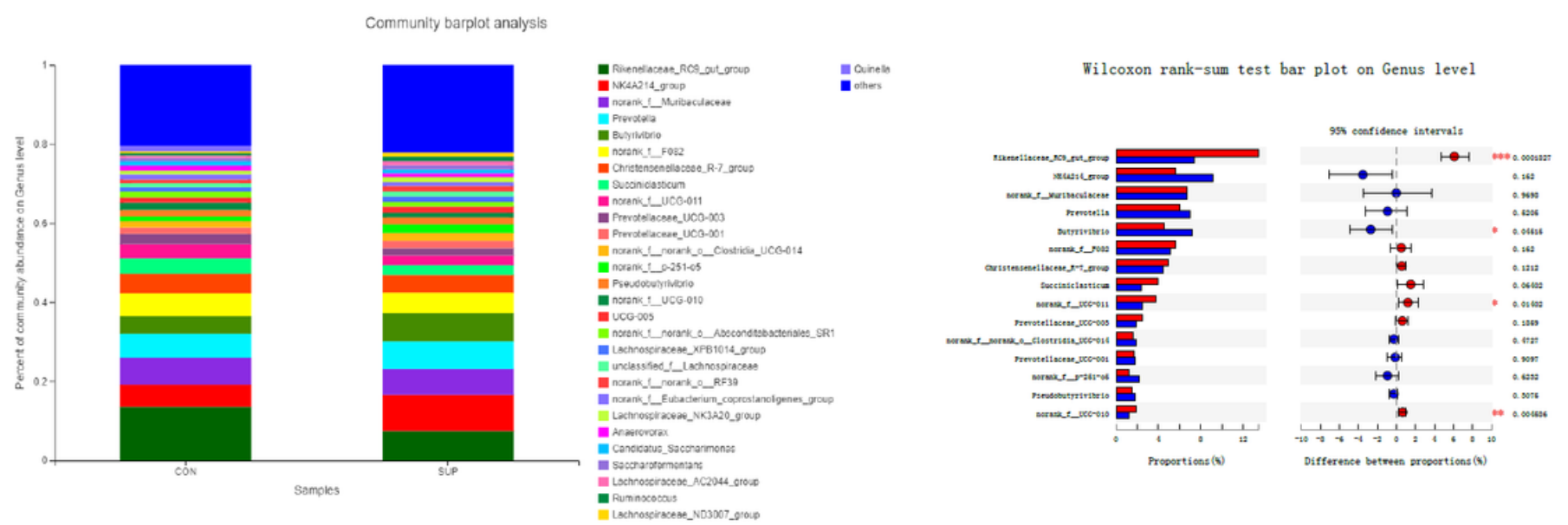

\section{Figure 3}

Distribution of bacteria in different groups. The color-coded bar plots represent the average distribution of bacterial phyla (a) and genera (b), respectively. Only the dominant bacteria (with a relative abundance $\geq 1 \%$ ) among rumen bacteria are shown. Extended error bar plots illustrate the mean proportions and differences in the phyla (c) or genera (d) in rumen samples. * indicates $p<0.05$ 